\title{
Relato de caso de leucemia de células pilosas
}

Case report of hairy cell leukemia

Lacy Cardoso de Brito Junior'; Suane Reis Barbosa²; Larissa Tatiane Martins Francês ${ }^{3}$

unitermos

Neoplasias de células B

maduras

Células pilosas

Imunofenotipagem

Citometria de fluxo

\section{resumo}

A leucemia de células pilosas (LCP) é um tipo raro de linfoma não Hodgkin de células B. O quadro clínico inclui esplenomegalia, pancitopenia e linfocitose. Estudos de carcinogênese da doença revelam sua associação a agentes químicos agrícolas. $\mathrm{O}$ objetivo deste estudo foi o relato de um caso de paciente com LCP, masculino, tratorista, com pancitopenia, lesões de pele, sem esplenomegalia e com marcadores positivos para linfócitos B (CD19, CD20, CD22, CD79b, CD23, Lambda, imunoglobulina M [lgM], CD25 e CD103). Embora a LCP seja uma doença rara, a demora em seu diagnóstico pode levar a sérias complicações e à morte do paciente antes do diagnóstico.

\section{abstract}

Hairy cell leukemia (HCL) is a rare type of B-cell non-Hodgkin's lymphoma. The clinical symptoms include splenomegaly, pancytopenia, and lymphocytosis. Studies on its carcinogenesis reveal association with exposure to agricultural chemical agents. The objective of this study was to report the case of a male patient, tractor operator, diagnosed with HCL, pancytopenia, cutaneous lesions, without splenomegaly and positive markers for B-cell lymphocytes (CD19, CD20, CD22, CD79b, CD23, Lambda, immunoglobulin M [IgM], CD25 and CD103). Although $\mathrm{HCL}$ is a rare disease, late diagnosis may ultimately lead to severe complications and patient's death.

\section{key words}

Mature B-cells neoplasms

Hairy cell leukemia

Immunophenotype

Flow cytometry

1. Doutor em Ciências Médicas com ênfase em Patologia Experimental pela Faculdade de Medicina de Ribeirão Preto/Universidade de São Paulo (USP); professor adjunto IV da Universidade Federal do Pará (UFPA).

2. Biomédica.

3. Especialista em Hematologia; gerente do Laboratório de Hematologia da Fundação HEMOPA. 


\section{Introdução}

A leucemia de células pilosas (LCP) é uma doença linfoproliferativa crônica que corresponde a $2 \%$ de todas as leucemias linfoides do adulto, sendo mais comum em homens (5:1) com idade média de 55 anos $^{(22)}$. Caracteriza-se pela infiltração das células $B$ neoplásicas na medula óssea $(\mathrm{MO})$, associada à punção aspirativa seca da $\mathrm{MO}$ decorrente da fibrose reticulínica( ${ }^{(1)}$, além de pancitopenia importante, monocitopenia e suscetibilidade a infecções por Aspergillus, Histoplasma, Cryptococcus e Pneumocystis carinie esplenomegalia ${ }^{(10)}$. Ocasionalmente, pode ocorrer adenomegalia e hepatomegalia em estágios avançados da doença e manifestações cutâneas ${ }^{(17)}$.

A patogênese da LCP ainda não está totalmente elucida$\mathrm{da}^{(3,15)}$, contudo, estudos recentes sugerem a associação da patogênese da LCP a fatores ocupacionais relacionados com exposição a substâncias químicas (solventes, herbicidas, fungicidas, agentes impregnantes) da atividade agríco-

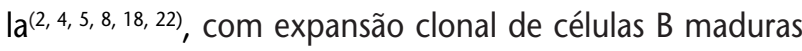
neoplásicas que apresentam expressão restrita de cadeia leve da imunoglobulina $(\lg )^{(7)}$ e mutada do gene da região variável da cadeia pesada de imunoglobulina $(\operatorname{lgVH})^{(19,20)}$.

O diagnóstico baseia-se na presença de esplenomegalia ${ }^{(21)}$ e no achado de linfócitos vilosos no sangue periférico e na $\mathrm{MO}$, com reação citoquímica positiva para fosfatase ácido tartarato-resistente (FATR), a qual não é achado específico para $\mathrm{LCP}^{(15)}$, além da biópsia da $\mathrm{MO}$, que pode se apresentar hipercelular ou hipocelular, com infiltrado difuso ou focal de células mononucleares com citoplasma abundante (células espaçadas) e aumento de reticulina ${ }^{(15)}$.

O diagnóstico da LCP, porém, é confirmado pela imunofenotipagem por citometria de fluxo, uma metodologia capaz de demonstrar a capacidade de expressão das imunoglobulinas de superfície $\operatorname{lgM}, \lg \mathrm{D}$ ou $\lg \mathrm{A}$, além de outros antígenos associados às células $B$, como CD19, CD20, CD22 e CD79b, ou típicos da LCP, como CD25, CD11 c e CD103, com expressão variável de FMC-7 e CD5, CD10 e CD23 negativas $(1,6,11,12,16,21)$.

Assim, os objetivos deste estudo foram promover o relato de um caso de paciente com LCP com marcadores positivos para linfócitos $B$, que apresentava lesões de pele, sem esplenomegalia, e revisar alguns aspectos relacionados com essa doença.

\section{Relato de caso}

Homem, 40 anos de idade, trabalhador da agricultura, tratorista como ocupação principal, município de Balsas
(MA). Ao atendimento em 5 de maio de 2010, no Serviço de Hematologia da Fundação HEMOPA, apresentava história clínica de perda de peso, astenia intensa e piora progressiva do estado geral.

Ao exame físico apresentava lesões cutâneas escamativas em membros inferiores, com exames de imagem de ultrassonografia abdominal e raio $\mathrm{X}$ do tórax negativos para visceromegalias.

São agendados e realizados exames laboratoriais de admissão ao serviço em 7 de maio de 2010 e retorno do paciente para 11 de maio de 2010. Os exames realizados revelavam:

- hemograma associado à pancitopenia com eritrócitos $=3,02$ milhões $/ \mathrm{mm}^{3}$; hemoglobina $=10 \mathrm{~g} / \mathrm{dl}$; hematócrito $=29,8 \%$; red cell distribution width $(R D W)=29,7 \%$; plaquetas $=100 \mathrm{mil} / \mathrm{mm}^{3}$; leucócitos $=1.400 / \mathrm{mm}^{3}$ e diferencial leucocitária com $52 \%$ linfócitos, $40 \%$ segmentados, $7 \%$ monócitos e $1 \%$ bastões;

- sorologias negativas para doença de Chagas, vírus da imunodeficiência humana (HIV) I/II, vírus T-linfotrópico humano (HTLV) I/II, sífilis e hepatites;

- testes para fator antinuclear, autoanticorpos RNP/Sm, Ro/SS-A e La/SS-B, anti-DNA, fator reumatoide e antiestreptolisina $\mathrm{O}$, todos não reagentes;

- dosagem de proteínas totais e frações alteradas, aumento de globulinas $(4,37 \mathrm{~g} / \mathrm{dl})$ e teste para proteína $C$ reativa positivo $(11,3 \mathrm{mg} / \mathrm{l})$.

Ao retorno, após um mês, em 8 de junho de 2010, o paciente apresentava tosse, febre e dores ósseas, articulares e torácicas. O hemograma revelou agravo da pancitopenia com plaquetas $=64 \mathrm{mil} / \mathrm{mm}^{3}$; eritrócitos $=2,7 \mathrm{milhões} / \mathrm{mm}^{3}$; hemoglobina $=9 \mathrm{~g} / \mathrm{dl}$; hematócrito $=27 \%, \mathrm{RDW}=20 \%$; leucócitos $=1.300 / \mathrm{mm}^{3}$ e manutenção do padrão da diferencial leucocitária com $51 \%$ linfócitos, $38 \%$ segmentados e 9\% monócitos.

O mielograma realizado em 11 de junho de 2010 demonstrou hipocelularidade do setor megacariocítico, com plaquetogênese reduzida, e do setor linfoplasmocitário, com predomínio de células pilosas de citoplasma basofílico, azul acinzentado, com bordas irregulares, apresentando projeções semelhantes a pelos, sugestivo de LCP. A biópsia de $\mathrm{MO}$ realizada na mesma época revelou medula normocelular compatível com a idade, com infiltração difusa de células linfoides semelhantes à LCP.

O exame de imunofenotipagem por citometria de fluxo do sangue periférico, realizado em 16 de junho de 2010, 
demonstrou a presença de populações celulares com expressão para CD19, CD20, CD22, CD23, CD45, CD79b, CD25, CD103, Lambda e lgM (Figura), com ausência de expressão para FMC-7, Kappa e IgG, confirmando a suspeita de LCP. O paciente foi encaminhado para o Serviço de Hematologia do Hospital Ophir Loyola para tratamento quimioterápico em 25 de junho de 2010.

\section{Discussão}

O diagnóstico da LCP, segundo dados da literatura, é raro em função de sua baixa incidência (2\%) entre as leucemias linfoides do adulto(9, 21), sendo ainda maior a responsabilidade dos profissionais de saúde na observação e no diagnóstico preciso dessa patologia.

Inúmeros são os relatos de estudos de caso-controle que sugerem como possíveis fatores de risco para o desenvolvimento dessa neoplasia atividades ocupacionais relacionadas com trabalhos realizados na agricultura, em função da exposição que esses trabalhadores têm aos diversos agentes químicos, como os pesticidas ${ }^{(8,13,14)}$. Embora esse fato não tenha sido avaliado diretamente neste relato de caso, coincidência ou não, o paciente era tratorista em um município que se destaca por forte produção de grãos (Balsas-MA), em especial a soja ${ }^{(13,18)}$.

Os achados de pancitopenia (anemia, leucopenia e trobocitopenia progressivas), observados também neste relato de caso, são complicações hematológicas bastante comuns na LCP, assim como os sinais morfológicos e de celularidade da $\mathrm{MO}$ observados nesse paciente, corroborando com a literatura ${ }^{(21)}$.

A esplenomegalia, outro achado frequente nessa patologia(10), não foi observada no caso relatado, enquanto as lesões cutâneas escamativas e os sinais de dores óssea e articular, observados nesse paciente, fazem parte das apresentações clínicas menos comuns da $\operatorname{LCP}(10,17)$.
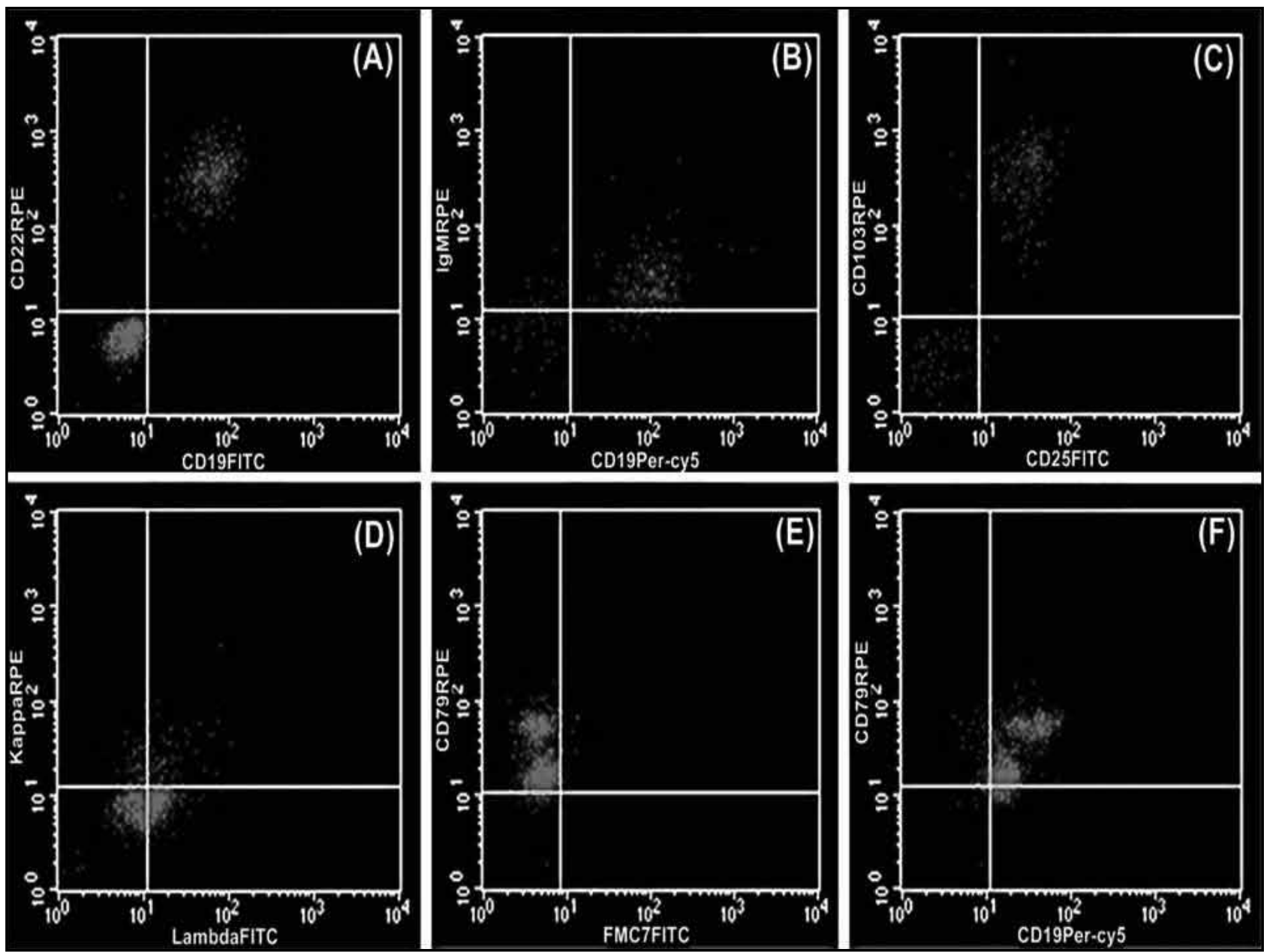

Figura - Histogramas de imunofenotipagem por citometria de fluxo com populações celulares apresentando expressões para (A) CD19 e CD22; (B) IgM e CD19; (C) CD103 e CD25; (D) Lambda, sem expressão de Kappa; (E) CD79, sem expressão de FMC7; (F) CD19 e CD79

IgM: imunoglobulina $M$. 
O uso da citometria de fluxo, aliada a achados clínicos, morfológicos e de imagem, mostraram-se ferramentas importantes no diagnóstico diferencial da LCP em relação a outros tipos de neoplasias linfoides de células B maduras $(6,21)$, principalmente pela associação a antígenos específicos de maior expressão na LCP, como CD20, CD45, CD79b, CD25 e CD103 $3^{(1,12)}$.
O relato de caso apresentado evidenciou a importância dos fatores de risco associados à $\mathrm{LCP}$, bem como revisou os aspectos clínicos menos frequentes dessa neoplasia. Além disso, permitiu demonstrar que a imunofenotipagem por citometria de fluxo é uma ferramenta essencial no diagnóstico, na classificação e na caracterização diferencial da LCP em relação às outras neoplasias de células $B$ de morfologia semelhante, como o linfoma de células esplênicas.

\section{Referências}

1. BACAL N. S. et al. Citometria de fluxo: imunofenotipagem em 48 casos de leucemia de células cabeludas e a relevância das intensidades de fluorescências nas expressões dos anticorpos monoclonais para 0 diagnóstico. Einstein, v. 5, n. 2, p. 123-8, 2007.

2. BOFFETTA, P.; VOCHT, F. Occupation and the risk of nonHodgkin lymphoma. Cancer Epidemiol Biomarkers Prev, v. 16, n. 3, p. 369-72, 2007.

3. CHEN, Y. H. et al. Immunophenotypic variations in hairy cell leukemia. Am J Clin Pathol, v. 125, p. 251-9, 2006.

4. CLAVEL, J. et al. Farming, pesticide use and hairy-cell leukemia. Scand J Work Environ HIth, v. 22, p. 28593, 1996b.

5. CLAVEL, J. et al. Hairy cell leukaemia and occupational exposure to benzene. Occup Ensiron Med, v. 53, p. 533-9, 1996a.

6. CRAIG, F. E. et al. Flow cytometric immunophenotyping for hematologic neoplasms. Blood, v. 111, n. 8, p. 3941-67, 2008.

7. FORCONI, F. et al. Hairy cell leukemia: at the crossroad of somatic mutation and isotype switch. Blood, v. 104, p. 3312-7, 2004.

8. FRITSCHI, L. et al. Occupational exposure to pesticides and risk of non-Hodgkins lymphoma. Am J Epidemiol, v. 162, p. 849-57, 2005.

9. KONDO, H.; TAKEUCHI, H.; KATAYAMA, I. Differentiating atypical HCL from HCL-Japanese variant [letter]. Leukemia, v. 10, p. 384, 1996.

10. KRAUT, E. H. Clinical manifestations and infectious complications of hairy-cell leukaemia. Best Pract Res Clin Haematol, v. 16, p. 33-40, 2003.

11. LAURENCE, D. M. et al. Cutaneous lesions in hairy-cell leukemia: case report and review of the literature. Arch Dermatol, v. 119, n. 4, p. 322-5, 1983.

12. MATUTES, E. New additions to antibody panels in the characterizations of chronic lymphoproliferative disorders. J Clin Pathol, v. 55, n. 3, p. 180-4, 2002.

13. NORDSTRÖM, M. et al. Occupational exposures, animal exposure and smoking as risk factors for hairy cell leukemia evaluated in a case-control study. Br J Cancer, v. 77, n. 11, p. 2048-52, 1998.

14. ORSI, L. et al. Occupational exposure to pesticides and lymphoid neoplasms among men: results of a French case-control study. Occup Environ Med, v. 66, n. 5, p. 291-8, 2008.
15. RAVANDI, F.; O'BRIEN, S. Chronic lymphoid leukemias other than chronic lymphocytic leukemia: diagnosis and treatment. Mayo Clin Proc, v. 80, p. 1660-74, 2005.

16. REGO, M.; SANTOS, G. A. S. Papel da imunofenotipagem por citometria de fluxo no diagnóstico diferencial das pancitopenias e das linfocitoses. Rev Bras Hematol Hemoter, v. 31, n. 5, 81-92, 2009.

17. SATTAR, M. A.; CAWLEY, M. I. D. Arthritis associated with hairy cell leukemia. Ann Rheum Dis, v. 41, p. 289-91, 1982.

18. SCHLESINGER, S.; NUNES, S. P.; CARNEIRO, R. Agricultura familiar da soja na região sul e o monocultivo no Maranhão: duas faces do cultivo da soja no Brasil. Rio de Janeiro: Fase, 2008. 148 p.

19. THORSELIUS, M. et al. Heterogeneous somatic hypermutation status confounds the cell of origin in hairy cell leukemia. Leuk Res, v. 29, p. 153-8, 2005.

20. VANHENTENRIJK, V. et al. VH gene analysis of hairy cell leukemia reveals a homogeneous mutation status and suggests its marginal zone B-cell origin. Leukemia, v. 18, p. 1729-32, 2004.

21. WANKO, S. O.; CASTRO, C. Hairy cell leukemia: an elusive but treatable disease. Oncologist, v. 11, p. 780-9, 2006.

22. ZAHM, S. H. et al. A case-control study of non-Hodgkins lymphoma and the herbicide 2,4-dichlorophenoxyacetic acid (2,4-D) in Eastern Nebraska. Epidemiology, v. 1, p. 349-56, 1990. 